\title{
Application Research on the Three Independent Learning Method in the Pharmaceutical Management Experimental Course Teaching
}

\author{
Shubing QIU* \\ School of Management and Engineering Institution, Anhui Polytechnic University, China.
}

\begin{abstract}
Background: In order to reform practical teaching about the pharmaceutical management experimental course, to make an investigation and analysis of the students' three independent learning ability status in the environment of "Know-all pharmacy V2.0" software, and to provide a new theoretical basis for the pharmaceutical management experimental course teaching. The results show that the "three independent learning" method is obviously more effective and superior than the traditional teaching in the pharmaceutical management experimental course learning and teaching. Method: In addition, it has important research significance, in the process of the "pharmaceutical management experimental course" learning and teaching, to make the students master the learning method is more important than the content of it. The "three independent learning" method is "self-learning, self-management and self-development", and its core is to guide the students to play an active self-efficacy and self-regulation to equip students with scientific learning method. Conclusion: "Three independent learning" method can fully mobilize the students' thinking activities and enable students to achieve the sublimation of learning strategies and the rational development of effective learning strategies with their own motivation, and it is obviously more effective and superior than the traditional teaching in the pharmaceutical management experimental course learning and teaching.
\end{abstract}

Key words: Three Independent Learning Method, Pharmaceutical Management, Experimental Course Teaching, Countermeasures.

\section{INTRODUCTION}

In the process of the "pharmaceutical management experimental course" learning and teaching, to make the students master the learning method is more important than the content of it". The "three independent learning" method is "self-learning, selfmanagement and self-development", and its core is to guide the students to play an active self-efficacy and self-regulation to equip students with scientific learning method.

Western educators advocated "Three Independent Learning" method from 1960s, and it is initially formed the theory of Operation Concept, ${ }^{2}$ Phenomenological Point of View, ${ }^{3}$ Independent Will View, ${ }^{4}$ Cognitive Constructivist view, ${ }^{4}$ Vygotsky's concept of Self-regulated Learning, ${ }^{5}$ Social Cognitive View, ${ }^{6}$ Information Processing Concept. ${ }^{7}$ Among them, Mr. Zimmerman advocated the learning framework systematically, as "Three Independent Learning Method". Then, advocates further "Three Independent Learning" is the integration of learning methods, cognitive and regulation, self theory and so on. And "Three Independent" is not an event, but a process of the elements fusion, ${ }^{8}$ which are constituted of three models, namely "process model, learning process, self-regulation".

In China, "Three Independent Learning" has a late start, but it is developing rapidly, and has made many preliminary research results in some academic fields, as following:

\section{Study on the meaning of the "Three Independent" theory}

Mr. Zhou earliest introduced the "three independent learning theory" into China,
Submission Date : 03-12-2014 Revision Date : :22-06-2015 Accepted Date : :19-07-2015

DOI: 10.5530/ijper.50.1.7 Correspondence Address Shubing QIU

Management and

Engineering Institution, Anhui Polytechnic University, No8, Peiking Road, Wuhu City, Anhui Province, Post code: 241000 , China.

TEL: +8613093636336

E-mail:44528934@qq.com

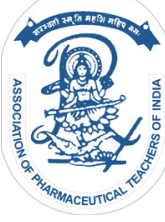

www.ijper.org 
and made a deeper study of its theoretical background and potential research value;' Mr. W. Ding demonstrated the problems of the environment structure, function and building path in the self-regulated learning process. ${ }^{10}$ In addition, it is necessary to discard the idea of "the independent learning is equal to self-taught, study on their own, home-educated out of the teachers", the deep meaning of the independent learning theory is focused more on the "learning attitude, learning ability and learning environment", and for the students, they also need the help of teachers. ${ }^{12}$

\section{The relationship between the "Three Independent Learning" dimensions}

This academic field includes (1) The relationship between the self-efficacy, classroom environment, academic achievement and academic ask; (2) The presentation reviewed of the self-regulatory development in abroad; (3) The effect of time pressure and the learning task on the actual self adjustment activities; (4) The relationship between motivation, self-regulation, selfefficacy, learning strategies. These studies have greatly promoted the study from a single cognition, motivation and behavior to integrate research.

\section{Research status}

For the present, more studies are focused on the field of common theoretical course, especially in terms of achievement motivation, self-efficacy, cognition, learning strategies and so on, but there are still many deficiencies in this academic field, for example, the current study is mainly in the general theory of curriculum-based, relatively few studies on experimental teaching and less teaching and research laboratory for Pharmaceutical Management.

\section{RESEARCH SURROUNDINGS ANALYSIS}

\section{Features of the pharmaceutical management major in China}

From the view of the major development direction, it can be divided into traditional major and emerging major, ${ }^{13-14}$ in which the traditional pharmaceutical majors include clinical medicine, new drug development, etc. And the emerging majors are as pharmaceutical management, including drug quality control, pharmaceutical marketing, pharmaceutical preparation processing and management, which are new intersect disciplines of pharmaceutical technology and management science in current information technology environment. ${ }^{15}$ And in the last eight years, students applying for this major have made a sustained and steady growth, and the students' employment rate is the highest in China in the last six years (affected university study period, the employment rate is of relative lag).

\section{Major development mac-environment analyses}

First, from the macro social environment, as the economy continues to grow, more and more people have become increasingly demanding of their own health. And China's pharmaceutical industry is growing annually with rapid development by average $16 \%$. In addition, most consumers do not understand pharmaceutical expertise, so in order to narrow the distance between consumers and products, it is urgent for strong professional background and high overall quality of compound talents, namely the pharmaceutical management major.

Second, with the popularization of network development, more and more students tend to play online games, but do not want to practice the boring experimental skills. As the expanding enrollment in recent years, given the realities of the student's own personality, skills, knowledge, experience and other aspects of diversity factors, how to take into account individual differences of students in the class of collective teaching organizational form, and develop all-round development of students proposes higher requirements for teaching methods of the pharmaceutical management experimental course.

\section{Features of the pharmaceutical management experimental course}

First, experimental course is different from the general theory teaching, the experimental course is a specific application of theoretical knowledge, focusing on students' practical and observation ability. In addition, Pharmaceutical management experimental teaching must take full account of the current status of the information technology and network technology environments in China, combined with the new learning platform specialized by the pharmaceutical management experiment software (currently China " Know-all pharmacy V2.0" software is used the most).

So, in this new situation, the traditional teaching model has been unable to meet the development requirements of progressive era, the focus of education must turn 
from "mere teacher impart knowledge" to "cultivate students' self-learning ability", and the "Three Independent Learning" , as a more suitable learning method to meet the educational requirements currently, is paid more and more attention among teachers and students.

\section{OBJECT OF STUDY AND TEACHING DESIGN Object of study}

Combined with " "Know-all pharmacy V2.0" software ", to take four classes (juniors) in two universities which set up "pharmaceutical management experiment course" in Anhui Province for example, and the students were randomly assigned into two groups, namely two experimental classes, two as control classes. The number of experimental classes is 36 and 37, and the control classes 36 and 37 .

\section{The experimental process control}

First, for the experimental class and control class, the teaching content, teaching hours, space, equipment and classroom teachers are all the same, and to use doubleblind control method in order to avoid the Hawthorne effect, and technical indicators are all use blind test with the same examiner before and after testing to ensure true and reliable test results.

\section{Data processing}

Before the experiment, the first of the students' basic quality of software testing, includes four module indicators score of pharmaceutical management experiment course, "Pharmaceutical technology base, user identification, management communication, integrated decision-making" (total score for each are as follows: 15 points, 30 points, 25 points, 30 points), and the resulting data will begin $\mathrm{T}$ test with results showing that the control class and experimental class are of no significant difference $(\mathrm{P}>0.05)$.

\section{Experiment design}

First, according to teaching programs of pharmaceutical management major and students' learning tasks requirements, the instructor make teaching plans and inform every student to guide themselves to use different learning strategies, and to simulate appropriate learning situation to help students achieve the established goals. Under the guidance of teachers, the students can develop their own learning plans and objectives from the index of "self-evaluation and monitoring, goal setting and strategic planning, policy enforcement and regulation, self-evaluation" etc.

\section{EXPERIMENTAL RESULTS ANALYSIS}

\section{The results}

After the experiment, the results of the control class and experimental class are showed in Table 1.

As is shown in Table 1, in the pharmaceutical management experimental teaching process, the experimental class score is better than the control class in the index of students" "comprehensive decision", and the difference was very significant $(\mathrm{P} \leq 0.01)$; and for the" User ID “and" Management Communication" score results, experimental classes are better than the control classes, and the difference was significant $(\mathrm{P}<0.05)$; and for "Pharmaceutical technology base" score results, experimental classes and control classes were not different extremely $(\mathrm{P}>0.05)$, which is mainly due to the "pharmaceutical technology" is a slow accumulation and improve process, and students' "pharmaceutical technology base" level cannot be very significant improved in the short term limited by the experiment time.

\section{Results analysis}

As seen above, in the pharmaceutical management teaching process, the application effect of "Three Independent Learning" method was better than traditional teaching, and the function was obvious in the students' learning process, expressed as follows:

\section{To help improve students' self-control}

With the "Three Independent Learning" method, the students, under the guidance of teachers, can set effective targets for pharmaceutical management experiential learning to increase interest in learning, and to increase the learning and training time consciously (as is shown in Table 2). The Table 2 shows that in the experimental class, the number of students who intent to increase training time consciously is 56 , significantly higher than the control class of 11 persons, the experimental results difference was significant, which shows that the students' learning confidence is improving, and willing to achieve higher goal effort. As a result, the students' self-control and self-discipline were improved significantly.

\section{To form students' good learning motivation}

Called "Three Independent Learning" method, the core of it is the students' self-development and to fully mobilize their own internal control and actively participate under the guidance of teachers. As is shown in Table 2 the questionnaire statistics on motivation of pharmaceutical 


\begin{tabular}{|c|c|c|c|c|}
\hline Variable & Classes & Numbers & $\bar{x}$ scores & $\mathbf{P}$ \\
\hline \multirow{2}{*}{$\begin{array}{l}\text { Pharmaceutical } \\
\text { technology base }\end{array}$} & experimental class & 73 & 26 & \multirow{2}{*}{$>0.05$} \\
\hline & Control class & 73 & 22 & \\
\hline \multirow{2}{*}{ User identification } & experimental class & 73 & 25 & \multirow{2}{*}{$<0.05$} \\
\hline & Control class & 73 & 23 & \\
\hline \multirow{2}{*}{$\begin{array}{l}\text { Management } \\
\text { Communication }\end{array}$} & experimental class & 73 & 19 & \multirow{2}{*}{$<0.05$} \\
\hline & Control class & 73 & 18 & \\
\hline \multirow{2}{*}{ Integrated Decision } & experimental class & 73 & 13 & \multirow{2}{*}{$\leqq_{0.01}$} \\
\hline & Control class & 73 & 12 & \\
\hline
\end{tabular}

\begin{tabular}{|c|c|c|c|c|c|c|c|}
\hline \multicolumn{2}{|c|}{ Project } & \multirow{2}{*}{$\begin{array}{c}\begin{array}{c}\text { For } \\
\text { exam }\end{array} \\
26\end{array}$} & \multirow{2}{*}{$\begin{array}{c}\text { Improving } \\
\text { skills }\end{array}$} & \multirow{2}{*}{$\begin{array}{c}\begin{array}{c}\text { His own } \\
\text { hobby }\end{array} \\
18\end{array}$} & \multirow{2}{*}{$\begin{array}{c}\text { Believing in } \\
\text { learning well }\end{array}$} & \multirow{2}{*}{$\begin{array}{c}\text { Learning bad } \\
\text { because of his } \\
\text { own }\end{array}$} & \multirow{2}{*}{$\begin{array}{c}\begin{array}{c}\text { Willing to } \\
\text { increase }\end{array} \\
\text { learning time } \\
14\end{array}$} \\
\hline & $\begin{array}{c}\text { Before } \\
\text { experiment }\end{array}$ & & & & & & \\
\hline Numbers & $\begin{array}{c}\text { After } \\
\text { experiment }\end{array}$ & 6 & 59 & 54 & 68 & 50 & 56 \\
\hline \multirow{2}{*}{$\begin{array}{c}\text { Percentage } \\
(\%)\end{array}$} & $\begin{array}{c}\text { Before } \\
\text { experiment }\end{array}$ & 35.6 & 28.8 & 24.7 & 26.0 & 28.8 & 19.2 \\
\hline & $\begin{array}{c}\text { After } \\
\text { experiment }\end{array}$ & 8.2 & 80.8 & 74.0 & 93.2 & 68.5 & 76.7 \\
\hline
\end{tabular}

management experimental classes, before the experiment, $37 \%$ of the students consider "for examinations" as the main motivation of learning, indicating that many students just study for exam, not really recognizing the true value of the course. After the teaching experiment, except for examinations indicators, other indicators have greatly improved, indicating their practical ability and cognitive development of the experimental software has been significantly improved, and the awareness of students' independent learning skills is improved obviously. So, the "Three Independent Learning" method has a significant role in stimulating the students to form good study motivation.

\section{CONCLUSIONS AND PROSPECTS}

As shown above about the pharmaceutical management experiment course teaching, the "Three Independent Learning" method, which can fully mobilize the students' thinking activities and enable students to achieve the sublimation of learning strategies and the rational development of effective learning strategies with their own motivation, and it will make for a good help to improve the students' self-control by pushing them to do positive and active exercises consciously. Last we can see that the application results are obvious, and we can draw a conclusion that the "Three Independent Learning" method has a practical guidance effect, and it can stimulate the students' enthusiasm of learning effectively.

\section{ACKNOWLEDGEMENTS}

This work is partially supported by the National Foundation of Social Science of China (NO.14BGL163) and Anhui province university fund project (TSSK2014B24) and the Major projects of the humanities and social sciences research in Anhui Province (SK2015A278). The authors also gratefully acknowledge the helpful comments and suggestions of the reviewers, which have improved the presentation.

\section{CONFLICT OF INTEREST}

The author declare that I do not have any commercial or associative interest that represents a conflict of interest in connection with the work submitted.

\section{SUMMARY}

- The "three independent learning" method can fully mobilize the students' thinking activities and enable students to achieve the sublimation of learning strategies and the rational development of effective learning strategies with their own motivation.

- The "three independent learning" method is obviously more effective and superior than the traditional teaching in the pharmaceutical management experimental course learning and teaching.

- The "three independent learning" method can stimulate the students' enthusiasm of learning effectively.

- The "three independent learning" method has a good help to improve the students' self-control. 


\section{About Authors}

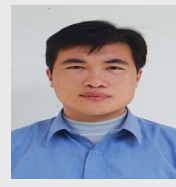

Shubing QIU, is the young and famous professor in the school of Management Engineering in Anhui Polytechnic University (China), and is well known in the field of educational management science, and in this academic field, and has published many articles in various journal such as Computer Modeling and New Technologies etc, and presented his research results at various important international conferences. And in recent years has successfully managed three national sponsored research projects and grants.

\section{REFERENCES}

1. Ju XL. A Graduate Program of Pharmaceutical Engineering Education in China. Indian Journal of Pharmaceutical Education and Research. 2010; 44(2): 121-25

2. Mace FC, Kratochwill TR. Self-monitoring: Applications and issues. In J. Witts. Elliott, \& F. Gresham (Eds.), Handbook of behavior therapy in education. New York: Pergamon Inc, 1988: 498-9.

3. McCombs BL, Vakili D. A learner-centered frame work fore-learning. Teacher College Record. 2005; 107(8): 1582-600.

4. Corno L. Self-regulated learning: a volitional analysis. Self-Regulated Learning and Academic Achievement. Springer Series in Cognitive Development. New York: Springer Inc, 1989: 111-41.

5. Paris SG, Byrnes JP. The constructivist approach to self-regulation and learning in the classroom. Self-Regulated Learning and Academic Achievement. Springer Series in Cognitive Development. New York: Springer Inc, 1989: 169-200.

6. Rohrkemper. Self-regulated learning and academic achievement. SelfRegulated Learning and Academic Achievement. Springer Series in Cognitive Development. New York: Springer Inc, 1989: 143-59.
7. Zimmerman BJ. Models of self-regulated learning and academic achievement. Self-Regulated Learning and Academic Achievement. Springer Series in Cognitive Development. 1989: 1-25.

8. Boekaerts M. Self-regulated learning: where we are today. Int J of Edu Res. 1999; 31(6): 445-57.

9. Zhou GT. Self regulated learning theory. Foreign Edu Materials. 1995; 01: 41-2.

10. Wei D. Self regulated learning and efficient learning environment. Foreign Edu Res. 2006; 01: 7-10.

11. Sun F. The meaning and theoretical basis of autonomous learning. Reform and Openning. 2011: 06: 156-8.

12. Zhang MQ. The reform of the college entrance examination system and the function of social education. China Examinations. 2015; 05: 3-7.

13. Cai LJ. Review and Prospect of the clinical pharmacy development history in China. Medicine \& Philosophy. 2010; 09: 79-80.

14. Ling Y. Reform and innovation on talent fosters mode for pharmaceutical major. Journal of Modern Medicine \& Health. 2012; 03: 449-50.

15. Duo $X$. Thinking on the cultivation mode of licensed pharmacist in China. Journal of Liaoning University of Traditional Chinese Medicine. 2015; 03: 76-9. 